\title{
Literatura y memoria visual: Cruces estético-performativos entre las narrativas de la memoria y el Estallido Social de octubre 2019
}

\section{Literature and visual memory: Aesthetic-performative chains between the narratives of memory and the October 2019 Social Uprising}

Joaquín Vargas ${ }^{2}$

\begin{abstract}
Resumen
El llamado Estallido Social, ocurrido entre octubre y diciembre de 2019 en Chile, puso de manifiesto la importancia de las contranarrativas urbanas que operan en contextos de lucha social y protesta (Márquez y Rozas, 2019). Entendidas como tales los rayados, pancartas y performance artísticas, las contranarrativas suponen una resignificación del espacio urbano, entendiendo a la ciudad en su calidad de discurso (Rama, 1998), que plantea una imagen homogénea de identidad a partir del monumento (Harvey, 1990). La discusión con dicho discurso evidencia una relación estético-performativa con las narrativas literarias de la memoria que se gestan desde los 90, donde la articulación de contraespacios (Locane, 2013) conlleva, también, un acto de resignificación del espacio. De este modo, el presente estudio supone una comparación entre el archivo visual del Estallido Social y los cruces estéticos que tiene con la literatura de la memoria. A partir de la lectura y análisis de autores como Bisama (Taxidermia, 2014), Celedón (La Filial, 2012), Sutherland (Papelucho gay en dictadura, 2019) y Fernández (Fuenzalida, 2012; Chilean Electric, 2015), vemos que las marcas de la ruina, la fotografía y la performance vienen a tensionar los signos hegemónicos establecidos en el diseño urbano, poniendo sobre la palestra el problema de la memoria y la identidad de quienes experimentan la ciudad.
\end{abstract}

Palabras clave: ciudad, protesta, literatura, ruina, fotografía

\begin{abstract}
The so-called Social Uprising, which took place between October and December 2019 in Chile, highlighted the importance of the urban counter-narratives operating in contexts of social struggle and protest (Márquez and Rozas, 2019). Understood as scratches, banners and artistic performances, the counter-narratives represent a resignification of the urban space that consider the city as discourse (Rama, 1998) and present a homogeneous image of identity based on the monument (Harvey, 1990). Addressing that discourse implies an aesthetic-performative relation with the literary narratives of memory that are set from the 1990s onwards, where the articulation of counter-spaces (Locane, 2013) also assumes an act of resignification of the space. In that way, this article is a comparison between the visual record of the Social Uprising and its

\footnotetext{
${ }^{1}$ Ponencia presentada en el XXIII Congreso Internacional de la Sociedad Chilena de Estudios Literarios (SOCHEL) Literatura y enseñanza en América Latina: reflexiones en torno a la equidad y la justicia, 6 al 9 de octubre de 2020. Las imágenes incluídas se corresponden a las proyectadas durante aquella jornada.

${ }^{2}$ Doctorado (c) en Estudios Americanos, Instituto de Estudios Avanzados (IDEA) de la Universidad de Santiago de Chile (USACh). ORCID: https://orcid.org/0000-0002-2751-7312 .Correo electrónico: joaquin.vargas.v@usach.cl
} 
Literatura y memoria visual: cruces estético-performativos entre las narrativas de la memoria y el Estallido Social de octubre 2019

\section{Joaquín Vargas}

aesthetic chains to the literature of memory. By reading and analyzing authors such as Bisama (Taxidermia, 2014), Celedón (La Filial, 2012), Sutherland (Papelucho gay en dictadura, 2019) and Fernández (Fuenzalida, 2012; Chilean Electric, 2015), we can see those traces of ruin, photography and artistic performance set in tension the hegemonic signs in the urban design, highlighting the problems of memory and identity of those who experience the city.

Key words: city, protest, literature, ruin, photography.

«Afuera caían cenizas. Otra vez Santiago manchado de gris.» Alia Trabucco Zerán, La Resta.

\section{Introducción}

En el comienzo de su libro La moral anarquista ([1891] 2014), Piotr Kropotkin afirma que la historia del pensamiento humano recuerda las oscilaciones del péndulo: "Después de un largo periodo de sueño viene el despertar" (Kropotkin, 2014, p. 5), donde el ser humano está dispuesto a soltarse de las cadenas con las que los 'interesados' (que él identifica con los gobernantes, magistrados y clérigos) le habían aprisionado. Kropotkin entiende este despertar como un cuestionamiento a las condiciones de vida en las que se encuentra el ser humano en determinada etapa, buscando la creación de 'nuevas ciencias', de nuevas interpretaciones y sentidos para su vida y la del pueblo en general. Sin ir más lejos, los eventos ocurridos durante octubre de 2019 en adelante en Chile no difieren de estas características descritas por Kropotkin, por cuanto una de las principales consignas del llamado Estallido Social fue la conocida CHILE DESPERTó, como se observa en la figura 1.

En este sentido, no es desconocido el hecho de que el Estallido Social de 2019 se sustenta en un espíritu de cambio total del sistema, según lo describe Gabriel Salinas en la presentación del libro Hasta que valga la pena vivir (2019), texto que condensa gran parte del archivo visual y las consignas que dieron inicio al estallido. Tal y como afirma Salinas,

Lo que esta primavera austral nos ha venido a decir es que la indignación asumida por millones de personas, y la rabia acumulada, pueden transformarse en prodigiosa fuerza creadora, precursora de lo nuevo, de aquella novedad que perdura, recogiendo los hilos de lo mejor que la cultura ha urdido, y diseñado motivos que la tradición no pudo tejer. (2019, p. 6).

Figura 1. En Echeverría, Rebolledo y Tótoro, 2019, p. 11.

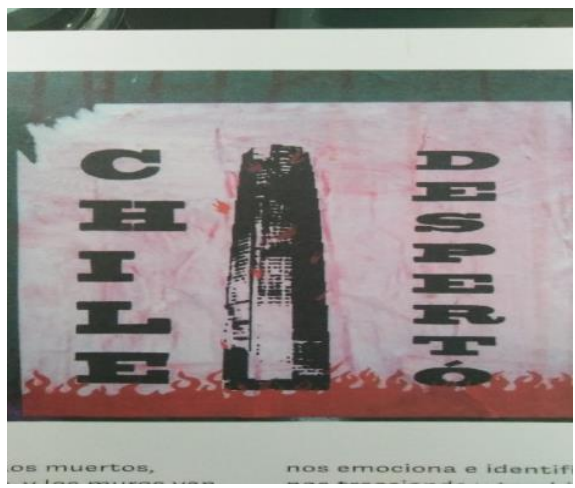




\section{Joaquín Vargas}

De este modo, conflictos como la educación, la salud, la precariedad en el sistema de pensiones o la deplorable situación del Sename, la lucha feminista, el movimiento LGBTIQ+, las deudas, las injusticias que quedaban en la impunidad, etcétera; se condensaron y -como la misma palabra lo establece- estallaron tras el alza injustificada de treinta pesos en el pasaje del metro. Sumado a los 'comentarios desfavorables' de los políticos del gobierno, la tarde del 18 de octubre de 2019 se convirtió de pronto en una fecha importante por cuanto, por primera vez luego de treinta años, la gente del país se levantó buscando decir 'basta': "El país comenzó a detenerse. El mismo 18 de octubre, las manifestaciones estallaron por todo Chile y también surgieron las primeras acciones extremas" (Echeverría et al., 2019, p. 9).

Este espíritu de cambio, claramente, se concentró -y se concentra hasta el día de hoy- en el cambio de la Constitución Política de la República de 1980 (según se observa en la figura 2), carta magna promulgada durante la dictadura militar y que, actualmente, se encuentra vigente. De esta forma, tal y como la dictadura de Pinochet motivó un sentido de refundación de la historia (cambio de constitución y remodelación del palacio de La Moneda), el Estallido culminaría en un nuevo proceso de refundación, tal y como se puede percibir tanto en el Plebiscito como en la acción de rebautizar la Plaza Italia como Plaza de la Dignidad.

Figura 2. En Echeverría, Rebolledo y Tótoro, 2019, p. 56.

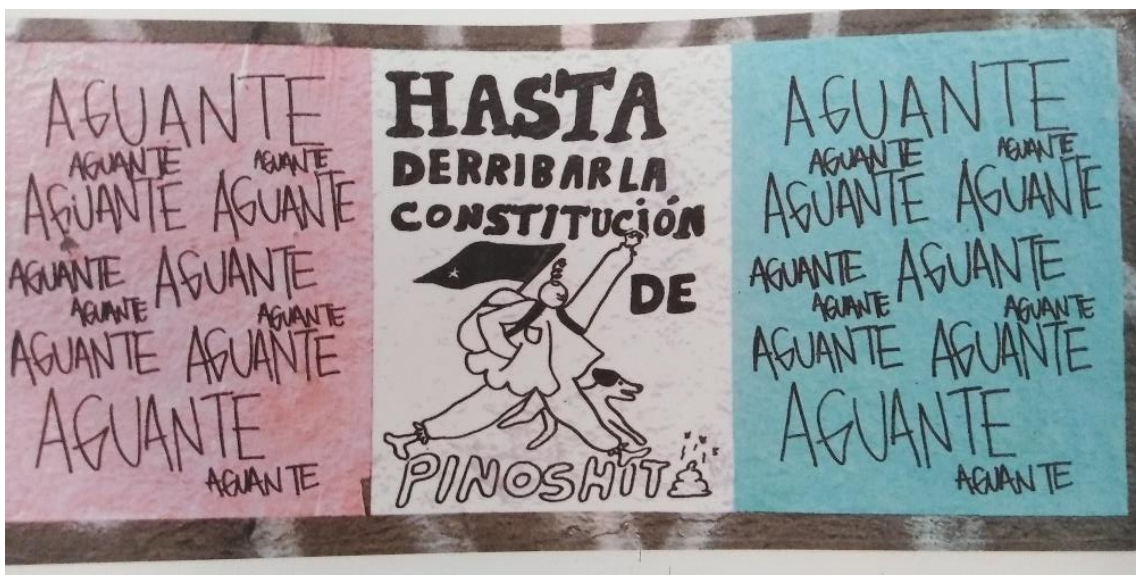

Ahora bien, el presente estudio no pretende un análisis de las circunstancias que anteceden y/o proceden al estallido social, sino una revisión del carácter estético-performativo del rayado y el escombro que podemos ver 'durante' el mismo pues, sostengo, hay en éstos una relación que vincula la lucha social con las reflexiones que se manifiestan en la literatura chilena reciente, sobre todo en la llamada narrativa de la memoria, con autores como Nona Fernández, Álvaro Bisama, Juan Pablo Sutherland o Matías Celedón. En otras palabras, el presente estudio pretende realizar un análisis comparativo que evidencia las relaciones entre la producción de un discurso contrahegemónico en el contexto de la lucha social, entendido por Márquez y Rozas como las contranarrativas urbanas, y la resignificación del espacio que se establece en la escritura literaria, lo que Lefebvre (en Locane, 2013) define como la articulación de contraespacios. El principal punto de contacto radicará en la articulación del paisaje y la visualidad de ambos campos, donde serán el uso de la ruina, de la fotografía y la performatividad como acto de resignificación, los que 
Literatura y memoria visual: cruces estético-performativos entre las narrativas de la memoria y el Estallido Social de octubre 2019

\section{Joaquín Vargas}

establecerán lo que podríamos plantear acá como un diálogo entre las formas de articulación de una memoria visual contrahegemónica.

\section{De las contranarrativas a los contraespacios, y viceversa}

En primer término, considero que en las novelas de la llamada Generación de los Hijos ${ }^{3}$, sobre todo en el Cono Sur, es posible plantear una conversación con la textualidad dada en el diseño urbano de la ciudad - principalmente, en su relación con las metrópolis de Santiago de Chile y Buenos Aires en Argentina-, por cuanto en los monumentos y patrimonios nacionales se puede identificar la construcción tanto de una narrativa nacional de nuestra identidad como de nuestra historia. No obstante, y como lo plantean Márquez y Rozas (2019), estas narrativas son capaces de despertar, a su vez, contranarrativas que, en su condición discursiva, se disputan el lugar con los discursos hegemónicos del patrimonio. Sostengo, en función del presente estudio, que estas narrativas y contranarrativas pueden ser leídas desde un enfoque literario si se les considera en su condición de enunciado, según lo define Bajtín (2011); esto es, la forma en la que se presenta todo discurso inmerso dentro de un circuito comunicacional ${ }^{4}$ como lo es, tal como lo he planteado, la relación entre el diseño urbano y las novelas de la literatura chilena y argentina reciente.

En este sentido, será importante identificar cómo se articulan las narrativas y contranarrativas del diseño urbano, y cómo éstas se relacionan con sus respectivas reconstrucciones en la literatura. Para dicho efecto, partimos de la lectura que David Harvey (1990) realiza de la ciudad en su condición posmoderna, dentro de los contextos de posguerra en Europa y Estados Unidos. En su lectura, Harvey establece una oposición entre la ciudad moderna y la posmoderna, entendiendo que la primera se muestra organizada y funcional, sin acatar la diversidad y heterogeneidad de los grupos sociales, generando espacios estéticamente incómodos y marginales. La ciudad posmoderna, en cambio, se revela en su fragmentariedad pues busca formas estéticas para dar cuenta de la diversidad en los grupos sociales. De este modo, la ciudad se concibe como un collage de formas pasadas superpuestas unas a otras, donde el diseño urbano considera las experiencias individuales y particulares del sujeto en tanto cliente. No obstante, frente a esta imagen de collage destaca la idea, a partir de Harvey, de que la ciudad se concibe como un discurso que busca homogeneizar una idea de identidad a partir del diseño urbano.

Esta noción ya estaba presente en la teoría de Ángel Rama al establecer la gestación de la llamada ciudad letrada, donde la urbe -real- puede, efectivamente, ser leída en su clave simbólica, discursiva. Tenemos, así, en Latinoamérica, dos ciudades operando desde su fundación en la colonia:

\footnotetext{
${ }^{3}$ El término es acuñado por Lorena Amaro en su estudio "Formas de salir de casa, o cómo escapar del Ogro: relatos de filiación en la literatura chilena reciente" (2013) a partir del concepto de relatos de filiación, donde se establece una construcción de la memoria sosteniendo a los recuerdos de infancia como su 'locus' predilecto. Desde este punto de vista, se establece un cambio donde ya no se hace una investigación de la interioridad del narrador, sino de su anterioridad familiar, en una clara crítica a la herencia familiar y social.

${ }^{4}$ Bajtín establece una crítica a los estudios lingüísticos previos a su trabajo donde se releva la importancia que tiene el oyente y su consecuente respuesta dentro del circuito comunicacional, ententiendo que dicho carácter no es esencial para el lenguaje. Por ello, el autor refuta esta idea entendiendo que todo hablante presupone "la existencia de enunciados precedentes, propios y ajenos, con los cuales su enunciado de una u otra forma se relaciona (se apoya en ellos, polemiza con ellos, simplemente los supone ya sabidos por el oyente). Cada enunciado es el eslabón de una cadena, muy complejamente organizada de otros enunciados" (Bajtín, 2011, p. 24). A partir de esta idea, sostengo el carácter comunicacional que existe entre la literatura y el diseño urbano en su calidad de discurso, como se plantea a partir de la lectura de Ángel Rama.
} 


\section{Joaquín Vargas}

[...] la [ciudad] física que el visitante común recorre hasta perderse en su multiplicidad y fragmentación, y la simbólica que la ordena y la interpreta, aunque sólo para aquellos espíritus afines capaces de leer como significaciones los que no son nada más que significantes sensibles para los demás, y, merced a esa lectura, reconstruir el orden. (Rama, 1998, p. 40)

En esta condición discursiva de la ciudad (letrada), fragmentaria por su pretensión de abarcar la diversidad, aparece el monumento como un intento de homogeneizar el carácter identitario del sujeto inmerso en el espacio urbano. El monumento, según Harvey, implica el establecimiento de un mito - de un origen fundacional a nuestra identidad-a partir de la referencia histórica, tal como ocurrió con la llamada industria de la heredad en Gran Bretaña: "Los museos, las casas de campo, los paisajes urbanos reconstruidos y rehabilitados para que resulten ecos del pasado a integrar una vasta transformación del paisaje" (Harvey, 1990, p. 106). Dejando de lado la crítica que Harvey establece a la superficialidad del monumento, es posible ver que este posee esa marca de verdad que, a la larga, pretende articular una imagen positiva y calificada de un nosotros homogéneo. En otras palabras, se articula una narrativa de la sociedad que habita dentro del espacio urbano y su identidad, bajo el pretexto de selección que Tzvetan Todorov (2019) identifica con todo proceso de construcción de memoria ${ }^{5}$.

Sin embargo, y tal y como afirman Márquez y Rozas, "no solo el Estado es capaz de narrar, [...] pues los monumentos a menudo también se convierten en soportes para narrativas subalternas" (2019, p. 74). Las calles y monumentos de la ciudad, entonces, no sólo evocan la conmemoración histórica, sino que a su vez despiertan las llamadas contranarrativas a dichos relatos mediante el arte, la performance y la literatura. Consideradas como tales los rayados, intervenciones, movilizaciones y otros, las contranarrativas son aquellos paratextos ${ }^{6}$ que se disputan el lugar de la historia con el monumento, resignificando el espacio a partir de un cuestionamiento al sentido que, previamente, le habría otorgado el discurso hegemónico del momento, poniendo de manifiesto la lucha que se da al interior de la ciudad letrada de Rama:

Por la pared en que se inscriben, por su frecuente anonimato, por sus habituales faltas ortográficas, por el tipo de mensaje que transmiten, los graffiti atestiguan autores marginados de las vías letradas, muchas veces ajenos al cultivo de la escritura, habitualmente recusadores, protestatarios e incluso desesperados. (Rama, 1998, p. 50).

\footnotetext{
5 Todorov (2019) afirma que la memoria, bajo ningún punto de vista, se opone al olvido. Los términos, en este caso, son la supresión y la conservación, donde la memoria, como ejercicio, es una interacción entre ambos. Por ello es entendida como una selección, pues "algunos rasgos del suceso seán conservados; otros, inmediata o progresivamente marginados y luego olvidados” (p. 18). En función de este estudio, sostengo que la construcción identitaria que nace a partir del monumento mantiene la misma dinámica de selección de rasgos del pasado común.

${ }^{6}$ Entendido etimológicamente como aquello que acompaña al texto (para = junto a, al lado de), el 'paratexto' vendría a contribuir a la concreción del sentido del primero, funcionando como un dispositivo pragmático que "por una parte, predispone -o condiciona- para la lectura y, por otra, acompaña en el trayecto, cooperando con el lector en su trabajo de construcción -o reconstrucción-del sentido" (Alvarado, 1994, p. 3). Si bien se comprenden como tales los pie de página, prólogos, epígrafes y otros elementos similares, en función de este estudio entendemos también el rayado que acompaña al monumento por cuanto tensiona el carácter discursivo del mismo y su sentido en la articulación de la identidad.
} 


\section{Joaquín Vargas}

Así ocurre, por ejemplo, con los rayados que decoran los muros externos de la casa central de la Universidad de Chile, según se evidencia en la figura 3. Como huellas de pasadas movilizaciones sociales - marchas estudiantiles, marchas de los profesores, marchas feministas, marchas LGBTIQ+, y un largo etcétera- los muros de la Universidad condensan un espíritu de cambio y reclamo que resignifican el sentido institucional, académico y hermético, que la casa de estudios adquirió luego de la dictadura militar:

Emplazada en el centro de la Alameda, la universidad y sus muros son también marcados y signados por otros gritos y reclamos que se suman al de los estudiantes, dando así cuenta que el malestar y el enojo superan el sólo ámbito de la educación para desbordarse hacia dominios como el reclamo por la vivienda, la denuncia de los animalistas, feministas, pro aborto..., porque en esos muros se contiene el reclamo de todos [...]. (Márquez y Rozas, 2019, p. 56)

Figura 3. En diario El Ciudadano, 2012.

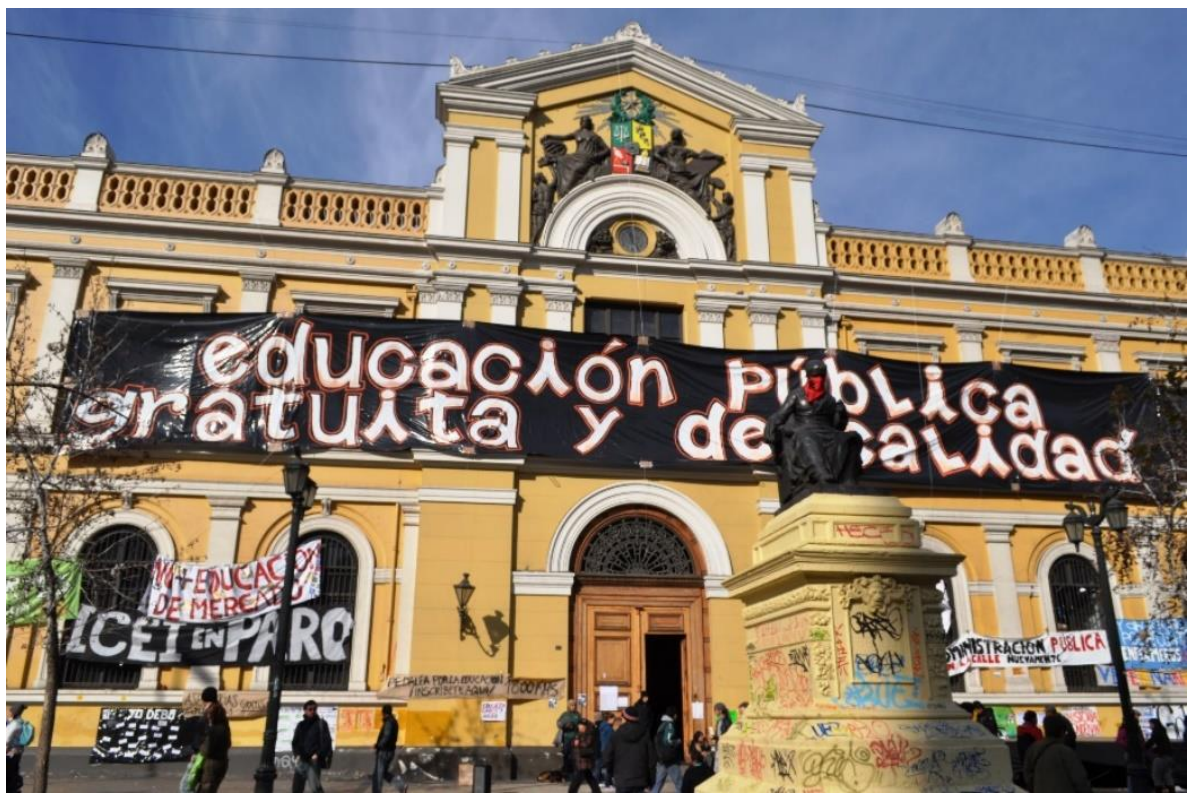

De esta forma, las contranarrativas urbanas buscan apropiarse de las calles, transformándolas y generando imágenes e imaginarios que "tensionan y amplían las representaciones del espacio público" (Fernández Droguett, 2019, p. 130). Existe todo un corpus de textos e imágenes que se plasman en los muros, en rayados, pancartas y fotografías que generan un nuevo sentimiento de identidad y propiedad para quienes habitan el espacio urbano, resignificándolo de la misma manera en que lo hacen las narrativas de la literatura reciente, pues ambas refieren, en cierta medida, a las huellas que el pasado dictatorial dejó en las calles de la ciudad.

Esta idea no es arbitraria. Leyendo a Henri Lefebvre, Jorge Locane (2013) establece una teoría para leer la representación de la ciudad en la narrativa latinoamericana reciente, considerando que en nuestro continente se marca un predominio por el espacio (lo muerto, lo inerte) al momento de constituir identidad. Según Lefebvre, y al igual que Harvey, los 
Literatura y memoria visual: cruces estético-performativos entre las narrativas de la memoria y el Estallido Social de octubre 2019

\section{Joaquín Vargas}

ordenamientos espaciales del diseño urbano implican un manejo ideológico por parte del poder hegemónico. No es menor, en este sentido, que Lefebvre considere la afección que conlleva la expansión acelerada del neoliberalismo global que se sucede desde 1989 en la mayoría de los países latinoamericanos, el cual hace de la desigualdad un valor (Locane, 2013, p. 117).

En este contexto, si el aspecto ideológico es crucial para comprender el ordenamiento espacial del diseño urbano, este necesariamente ha de componerse, también, de las representaciones y teorías que le otorgan significado y valor, razón por la cual Lefebvre le toma importancia a la literatura al momento de comprender la ciudad. En consecuencia, establece que ésta se construye en tres niveles: las prácticas espaciales, referentes a los usos cotidianos de los habitantes; las representaciones del espacio, que se corresponden a los diseños que los expertos hacen de acuerdo a un programa ideológico; y los espacios representacionales, entendidos como un "[...] repertorio de operaciones simbólicas y rituales tendientes a la resignificación y reapropiación de los espacios destinados en principio a ser experimentados pasivamente por los usuarios" (Locane, 2013, p. 118). Es en este último donde entra la literatura y el arte como mecanismos de producción de significados nuevos o codificaciones; es decir, sistemas de significados que se sobreimprimen, muchas veces, con un claro sentido contrahegemónico. A esto, Lefebvre lo define como la articulación literaria de contraespacios, los cuales pueden ser analizados a partir de la noción del «cronotopo», definido por Bajtín como «la intervinculación esencial de las relaciones temporales y espaciales asimiladas artísticamente en la literatura» (Bajtín, citado de Cisternas, 2010, p. 21).

Podemos destacar, por ejemplo, el trabajo realizado en el estudio de Carlos Franz, La muralla enterrada (2001), obra que rescata las lecturas literarias de las novelas del siglo XX en adelante, que refieren a la noción de hibridez que es posible observar por la separación de los distintos barrios de Santiago, aunque la obra de Franz no alcanza a dar cuenta de los cambios culturales que se sucedieron en las últimas dos décadas de la historia nacional, dentro del contexto del capitalismo tardío y crecimiento urbano. En cambio, un claro ejemplo de cómo se reconfigura el espacio urbano lo encontramos en la representación literaria del barrio La Chimba, presente en la novela Mapocho (2002) de Nona Fernández. Sobre esto, Andrea Jeftanovic (2007) establece una lectura que vincula la representación del espacio citadino en la obra de Fernández con las políticas del olvido, tal como lo veremos más adelante. Las nociones de una ciudad derruida y poblada por fantasmas, del barrio La Chimba como un repositorio de los residuos citadinos, y del río Mapocho como una arteria que arrastra los episodios de violencia ejercida contra el pueblo en la historia de Chile, dan cuenta del modo en que el espacio urbano -la ciudad real, según la plantea Rama- es rearticulado escrituralmente como espacio de denuncia, tal como ocurre con las manifestaciones y contranarrativas urbanas.

Sostengo, entonces, que hay una relación manifiesta entre las contranarrativas urbanas con las representaciones de la ciudad en la literatura y el arte, definidas por Lefebvre como contraespacios. Entre ambos se conjuga una resignificación del espacio, un cuestionamiento al sentido hegemónico del diseño urbano y una denuncia a las circunstancias sociopolíticas preponderantes en determinado contex to histórico. De este modo, podemos definir la relación entre ambos campos como un diálogo estético entre las formas de articulación literaria del paisaje citadino y la producción de una narrativa visual en el Estallido, en cuanto se genera un corpus de imágenes que reclaman las injusticias, ya sean del pasado como del presente. Dichas imágenes, ancladas tanto en las novelas recientes como en las calles de la ciudad, se componen de tres elementos que refieren el carácter artístico-performativo de las contranarrativas: una estética del 
Literatura y memoria visual: cruces estético-performativos entre las narrativas de la memoria y el Estallido Social de octubre 2019

\section{Joaquín Vargas}

residuo y la ruina, el uso de fotografías como registro y testimonio, y la performatividad como acto de resignificación del espacio, que en este caso refiere tanto a la fotografía misma como a la intervención y toma de la Plaza Dignidad.

\section{Ruina, fotografía y performatividad}

En primer lugar, hemos de entender que el carácter residual de la estética literaria en la narrativa del Cono Sur que se gesta desde los años 90 en adelante, responde al uso de las políticas de la memoria y técnicas del olvido que, en el caso de Chile, se formalizaron durante el periodo de la Transición, tal como lo define Nelly Richard (2001). Desde la instalación del neoliberalismo, uno de los móviles de la cultura nacional ha de ser la idea del progreso como medio de producción, comercialización y mercantilización social, económica y, por ende, cultural. Así, hasta la fecha, el país se ha movilizado en torno a la producción en masa de la novedad, y su consecuente producción en masa del desecho: el residuo, los restos, el arruinamiento de lo anterior, lo obsoleto, etc., serán parte también del acontecer y la escena citadina de Chile.

Conforme a esto, el residuo comienza a tomar también un sentido cultural: Raymond Williams (2000) entiende el concepto en su relación con las estructuras dominantes; el residuo es, en pocas palabras, aquel remanente del pasado que en su presencia viene a oponerse y a cuestionar la estructura dominante -tal como fueron definidas las contranarrativas urbanas-. En este sentido, la idea del desecho no sólo comulga con la idea de las producciones mercantiles, sino que además se desenvuelve dentro del margen del olvido. En el caso de Chile, pasado el periodo de la dictadura militar, se inició en el país una política institucional del borramiento de la memoria, en tanto el recuerdo del trauma se interrumpe con la idea del progreso, lo que se ve reflejado en el ‘blanqueamiento’ del palacio de La Moneda (Márquez y Rozas, 2019).

De esta forma, la narrativa de la memoria queda, a su vez, relegada, borroneada, desechada de la narrativa nacional y de las estructuras urbanas de la posdictadura. Lo que queda son los restos, los residuos de memoria o la memoria como un residuo, donde son el arte y la literatura quienes tematizan el fragmento de la memoria, en tanto pequeños escenarios de cuestionamiento a nuestra identidad: "[...] son a menudo el arte y la literatura los que recogen el desafío de convertir lo desunificado, lo inconexo y lo vagabundo de los restos en una "poética de la memoria"" (Richard, 2001, pp. 74-75. El destacado es del original).

Por ello, no es menor que el estallido social de 2019 haya hecho uso del arruinamiento y la "destrucción" del espacio como forma de protesta (figuras 4 y 5). Esto es bien analizado por Francisca Márquez (2020) al establecer una antropología del escombro dejado tras las manifestaciones de cada viernes en la Plaza Dignidad, entendiéndolo como una forma de tensionar y contradecir a la ciudad desde una narrativa de memorias subalternas: "Observar lo que se destruye y transforma en escombro es en cierto modo, un ejercicio de develamiento de las memorias ocultas que resisten al olvido y a las certezas" (p. 5). La ruina, en este caso, profundamente relacionada a la noción del escombro, figura como una oposición al lenguaje homogéneo del mercado y el neoliberalismo, tal como ocurre en novelas como Taxidermia (2014) de Álvaro Bisama o La Filial (2012) de Matías Celedón. 
Figura 4. De Mauro Veloso, 2019, p. 58.

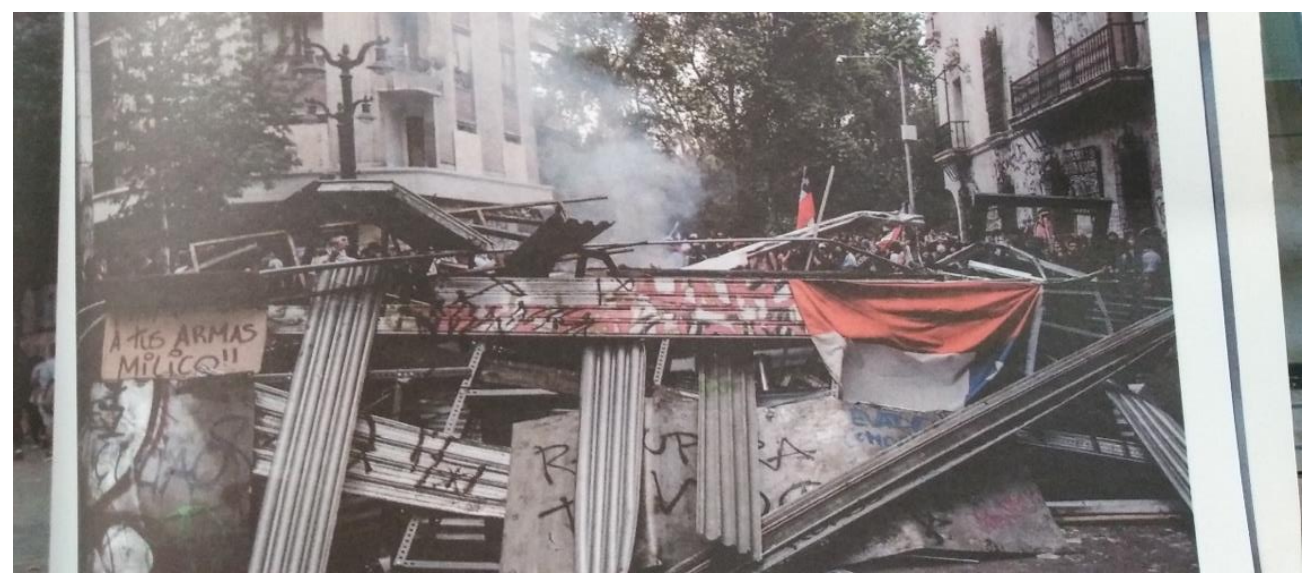

Figura 5. De Luis Hidalgo, 2019, p. 18.

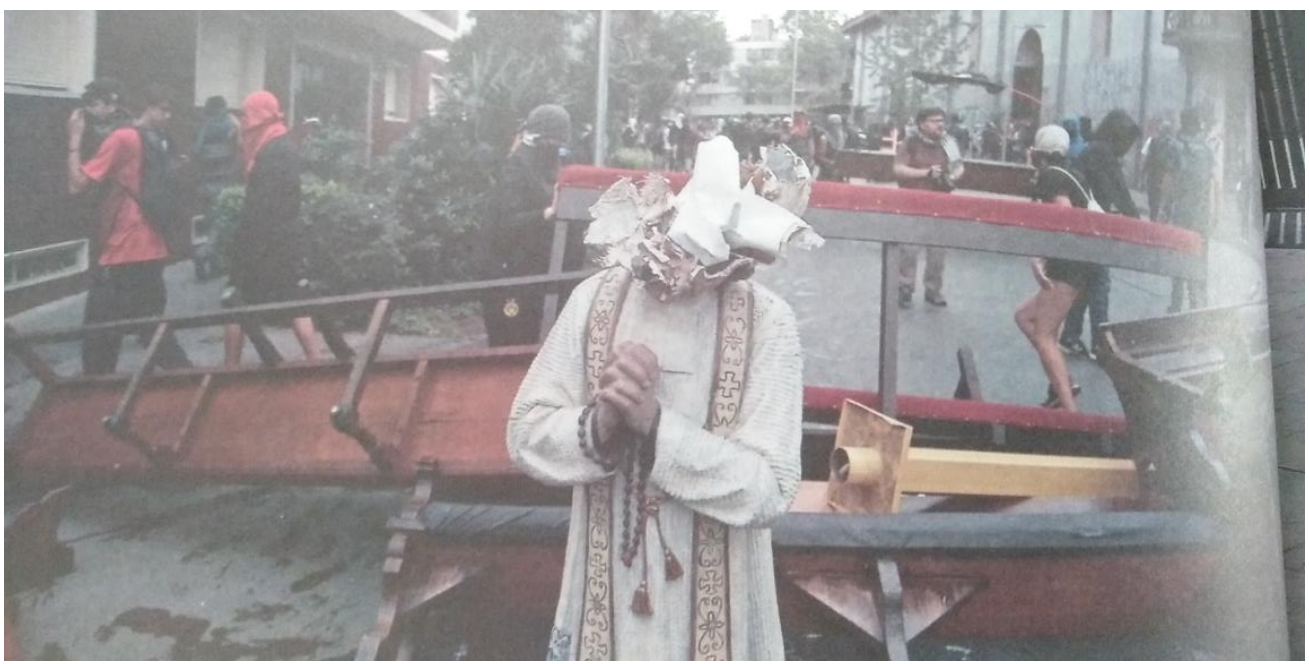

Es curioso que en ambas novelas se profundiza una crítica a la mecanización del sujeto, siendo esta una forma de alienación propia del capitalismo tardío, lo cual es mucho más evidente en La Filial que en Taxidermia. En esta última, sin embargo, ocurre algo interesante por cuanto la mecanización contempla la producción de imágenes e historias que revelan la violencia sistemática, alegorizada mediante el arruinamiento del cuerpo del caricaturista que protagoniza la historia. Dos elementos son importantes aquí pues, por un lado, el arruinamiento del cuerpo implica cicatrices y/o huellas, de la misma forma que los rayados y escombros generados en el estallido generan cicatrices y huellas en el cuerpo de la ciudad; por otro, de dicho arruinamiento deviene -o debería devenir- el cambio en la identidad del cuerpo:

A veces sueño que esa bolsa recibe patadas, combos, que alguien se acerca y se pone a apalearla. Yo estoy desnudo dentro. Y pienso en que esa es la única forma de contacto físico que tengo, la única manera de ser alguien: borrarme dentro de la bolsa, 


\section{Joaquín Vargas}

hacer que la tela del saco harinero manchada con tierra y sangre sea mi verdadera piel. (Bisama, 2012, p. 137)

La bolsa como repositorio del desecho, la violencia como única forma de contacto físico que conlleva arruinamiento del cuerpo - una estética marcada por lo sucio, con tierra y sangre en la piel- denotan esta experiencia corporal que relacionamos aquí con la memoria y la ciudad, estableciendo una nueva forma fenomenológica del ser en el lugar: "[...] todo proceso de ruinificación o ruinación (Errázuriz y Greene, 2018), entendido como material o artefacto objeto de destrucción o violencia, gatilla subjetividades y afectos residuales" (Márquez, 2020, p. 9). La 'ruinación' del cuerpo, en este sentido, tanto para la novela como para el espacio urbano, despiertan la idea de una identidad nueva, alterna y contrahegemónica.

Como afirma Natalia Anabalon (2016) en su lectura de Estrellas Muertas, en la obra de Bisama se constituye la memoria a partir de la experiencia y el cuerpo. Por ello, no es menor que la desfiguración del protagonista en Taxidermia se relacione con la violencia sistémica propia del neoliberalismo. El cuerpo, en este contexto, es concebido como soporte de poder, de modo que en él, en su superficie, queda inscrito el castigo en calidad de documento (Segato, 2013), permitiendo así la lectura de las consignas en función del poder hegemónico y la violencia expresiva.

Esta misma idea de la ruina es mucho más evidente en la obra de Matías Celedón, para la cual me sirvo del análisis a la noción del corte presentado por Sebastián Reyes (2020), por cuanto observo un funcionamiento similar en el paisaje del estallido. En su lectura de La Filial desde el conceptualismo, la noción del corte que surge de una escritura hecha eminentemente a partir de timbres se corresponden a un corte respecto a la realidad cotidiana del trabajo y su tiempo dentro de la sucursal en la que ocurren los hechos. De este modo, el corte como procedimiento de escritura contempla una crítica al neoliberalismo desde la forma y el material, del mismo modo que lo significó el estallido para la continuidad de la rutina.

Pero no sólo eso. Reyes propone que la técnica del corte en La Filial supone una combinación de lecturas entre segmentos verticales y segmentos horizontales en la lectura de la novela. Del mismo modo, se puede establecer esta lectura dentro de las pancartas y rayados que componen el escenario del estallido social. Los mensajes, consignas y denuncias que aparecen en éstos comprenden una narrativa que bien puede leerse en cada pancarta por separado, como en una seguidilla de pancartas que establecen un marco general del estallido y las denuncias que suscitaron la violencia de Estado (Márquez, 2020), como sucede con la frase NOS HAN DEJADO sOLOS (figuras 6 y 7), ubicada al inicio de la novela.

Figura 6. En Celedón, M. (2012) La Filial.

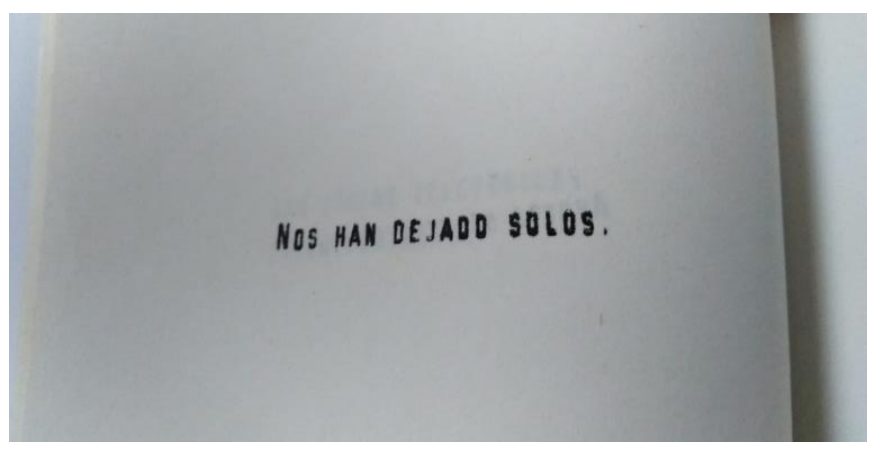




\section{Joaquín Vargas}

Figura 7. Echeverría et. al., 2019, p. 49.

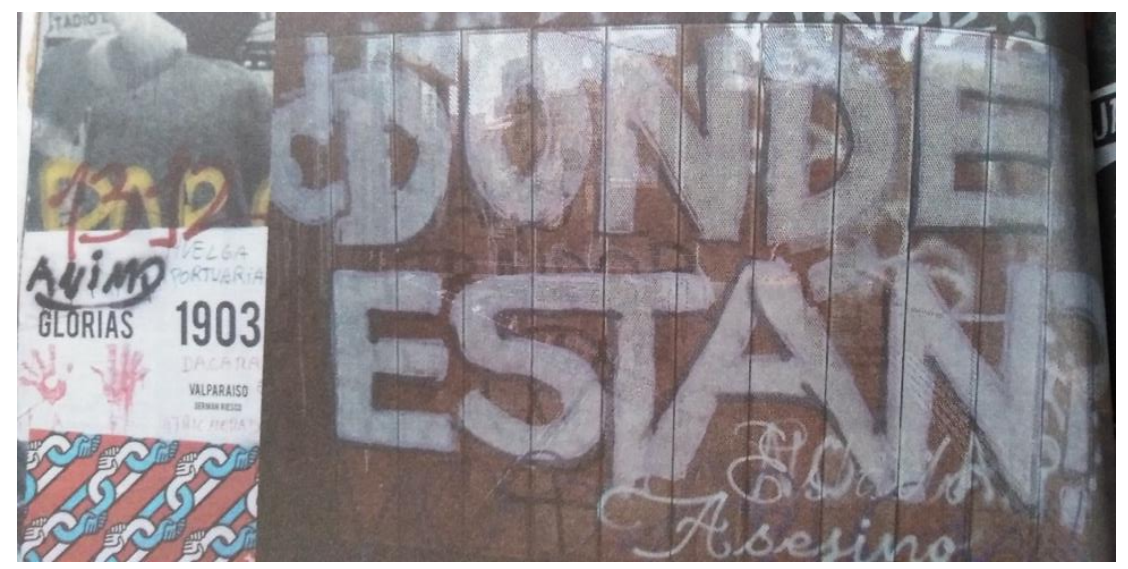

Así, mientras el timbre en la escritura de La Filial supone una resignificación, no solo del espacio (la sucursal) sino también del lenguaje (burocrático, de oficina), las pancartas y rayados de los muros suponen una resignificación en el momento en que se extraen frases y consignas sacadas de otros contextos (animación japonesa, películas de la cultura pop, canciones, e incluso las frases de los mismos políticos) para incluirlas en la manifestación social. Esta resignificación es, justamente, entendida por Reyes como un 'corte' respecto a la matriz de origen, una forma en que el hijo -del latín filius, por ello 'la filial'- queda abandonado a su suerte.

Por otro lado, entendiendo que el relato de Celedón cuenta la historia de un apagón (un 'corte' de luz) en una sucursal de trabajo, Reyes comprende que hay en esta una referencia al silenciamiento y blanqueamiento de la historia referente a la dictadura militar, por cuanto una de las fechas que aparecen en la novela es, justamente, la del 11 DE SEPTIEMBRE. Por lo demás, en aquellos años los apagones funcionaron como una herramienta común para el control del miedo en la población por parte del poder hegemónico. Así,

[e]se corte nos permite relacionar el estado de excepción (que hemos visto encontramos [sic] tanto aplicado a la sucursal, como al cuerpo del narrador con los electroshocks), con la vanguardia literaria y artística, y los conflictivos procesos de recuperación de la memoria, particularmente respecto a las violaciones de los derechos humanos durante la dictadura militar. (Reyes, 2020, p. 154).

De esta forma, y del mismo modo en que la escritura de La Filial encuentra en el corte y el timbre una forma de poder anteponerse a la imposibilidad del decir la memoria, durante el estallido social se encontró en las pancartas y rayados una forma de poder denunciar la represión y las violaciones a los derechos humanos ocurridos durante los meses de octubre a diciembre de 2019. Esto último adquiere una importancia particular, por cuanto las denuncias a las violaciones a los derechos humanos durante el estallido tienen un eco firme en las denuncias producidas durante los años de la dictadura.

En esta noción de la fragmentación y el corte podemos encontrar la aparición de la imagen fotográfica, tanto en las pancartas de las marchas como impresas sobre los muros de la Alameda y el centro de Santiago. Ya en los años de la dictadura militar, la aparición de los rostros y cuerpos de los detenidos desaparecidos en las fotografías que llevaban los familiares se convirtió en una 
Literatura y memoria visual: cruces estético-performativos entre las narrativas de la memoria y el Estallido Social de octubre 2019

\section{Joaquín Vargas}

forma de insistencia y resistencia que aclama por mantener viva la memoria de dichas víctimas. Es por ello que la fotografía y la imagen se ha convertido en el elemento que el arte utiliza para establecer el vínculo con la memoria a partir de las políticas del olvido. Opuesto a la imagen fugaz que nos invade desde la lógica del mercado, la fotografía refiere a ese elemento residual, a ese remanente del pasado que se niega a desaparecer y se opone a las estructuras dominantes.

En este contexto, Roland Barthes (2017) habla de spectrum -espectro, espectáculo- al referirse al objeto representado por la fotografía. La inmovilidad y permanencia del objeto, o del sujeto dado sea el caso, establece una fuerte relación entre la muerte y la animación -que podemos asociar a la idea de las ánimas en pena-. Así, Barthes plantea que la fotografía no es sino un testimonio de aquello que ha sido, afirmando su existencia en el pasado.

Por su parte, George Didi-Huberman (2004) realiza un estudio sobre cuatro fotografías que fueron tomadas durante agosto de 1944 en los campos de concentración de Auschwitz. Al respecto, presenta varias reflexiones sobre el tema de la fotografía como un "arrebato a la realidad" y una forma de anteponerse frente a lo 'indecible' o 'irrepresentable' de dicho episodio histórico. El mismo Barthes refiere a esto al enunciar que las fotografías le atraían por la "presión de lo indecible que quiere ser dicho" (2017, p. 48). De esta forma, Didi-Huberman considera que "la fotografía está asociada de por vida a la imagen y a la memoria: posee, pues, de ellas, la eminente fuerza epidémica" (2004, p. 44). La fotografía, en este sentido, ofrece un amplio contraste temporal donde confluyen el tiempo pasado con el presente; esto, si no consideramos el instante de su revelación y la noción de la reproducción que puede hacerse a partir del negativo (la 'fuerza epidémca'), tal como observa Nelly Richard.

En un trabajo previo, he analizado el recurso de la fotografía y la descripción ecfrástica ${ }^{7}$ dentro de la narrativa de Nona Fernández. En este contexto, las novelas de Fuenzalida (2012) y Chilean Electric (2015) toman la fotografía como recurso de escritura, por cuanto se establece un modo -y un medio- de hacerse cargo del problema de la memoria y su reproducción. Su articulación en la narrativa de Nona Fernández, entonces, estaría dado por el poder de enunciación que posee en tanto, como dice Barthes, testimonio del pasado.

Una fotografía siempre incrimina. Algo que sospechamos es demostrado irrefutablemente si aparece en una foto. No importa lo distorsionada que esté la imagen, tampoco cuales fueron las pretensiones del fotógrafo, ni sus aciertos o debilidades en el momento de disparar el obturador. Da lo mismo si está arrugada o desteñida, si se manchó o si alguien la cortó con una tijera. Una fotografía es siempre una huella. Una prueba de la escena del crimen. (Fernández, 2012, p. 43)

Ahora bien, el uso de la fotografía en Fuenzalida ha sido estudiado por Wolfgang Bongers a partir del concepto de la intermedialidad, como aquello que "designa la incorporación y conjugación de elementos de un medio viejo en uno nuevo, y viceversa" (2018, p. 106). La memoria, en este sentido, se torna profundamente intermedial en la medida que utiliza los medios de comunicación tecnológicos -cámara, televisión, computador- para su reconstrucción en la narrativa, como ocurre con autores como Jorge Baradit, Alejandro Zambra y, claramente, Nona Fernández, aunque podemos verla también en Álvaro Bisama y Juan Pablo Sutherland. En este contexto, "la fotografía reconfigura, a nivel temporal y espacial, la relación del ser humano con el

\footnotetext{
${ }^{7}$ Entiéndase el recurso ecfrástico como una representación verbal de una representación visual (Mitchell, 1994).
} 


\section{Joaquín Vargas}

mundo: una visión tipográfica [...] se vuelve visual e introduce una nueva temporalidad entre presencia y ausencia, entre vida y muerte" (p. 107).

En consecuencia, la persistencia de la memoria, en tanto denuncia de la violencia de Estado, se torna eminentemente intermedial; y es la fotografía, en este caso, la que cobra una importancia crucial, sobre todo para complementar la noción de testimonio: logra que lo dicho se torne representable, imaginable o incluso pensable. Su intervención en el espacio público, al igual que su uso como recurso estético en la escritura literaria, pone de manifiesto esta forma de insistencia y resistencia de la memoria, de forma que se combate la indiferencia frente al olvido que se ha establecido a partir de la publicidad y la imagen fugaz de los medios como la televisión. Y en el caso de las manifestaciones de 2019, podemos ver que son el internet y las redes sociales los nuevos medios de soporte para la denuncia a partir de un establecimiento del recuerdo desde la imagen del rostro y el cuerpo en su carácter fantasmagórico, que relacionamos con el spectrum bartheano, de quienes fueron víctimas directas de la violencia de Estado (figuras 8 y 9): los comuneros mapuches asesinados en democracia -entre los que destacó Camilo Catrillanca-, o los mutilados oculares durante el estallido, como Gustavo Gatica y Fabiola Campillai, en una represión que no hace sino recordar la violencia ejercida durante los años de dictadura, tal como lo manifiestan las pancartas y rayados.

Estos ecos del pasado se condicen con un episodio que toma lugar en la novela Chilean Electric (2015) de Nona Fernández, texto que incluye la fotografía como técnica de escritura utilizando el recurso ecfrástico de la narración- para resignificar el espacio de la Plaza de Armas a partir de la iluminación de los recuerdos y espacios oscurecidos por los discursos hegemónicos de la historia (Vargas, 2019). Entre dichos episodios, destaca uno que describe una manifestación pacífica acontecida en 1984, evento que declina en la mutilación ocular de un niño de catorce años por acción de Carabineros. Allí se describe la forma en que el joven pierde un ojo durante la protesta, y el modo en que todos lo rodean para registrar el acontecimiento con imágenes:

Uno de ellos le dijo al niño que se sacara las manos de la cara para hacerle una fotografía. El joven obedeció y se descubrió el rostro mostrando lo que, hasta ese momento, ninguno de nosotros había visto. Su ojo izquierdo estaba en el piso, tirado en el cemento, entremedio de la sangre igual que él. Un ojo izquierdo fuera de su órbita, fuera de su cuerpo, fuera de sus funciones. El cadáver de un ojo. Un ojo muerto. (Fernández, 2015, 50)

Figura 8. Fotografía de Gustavo Gatica, en Canal Sur Patagonia, 16 de noviembre de 2019.

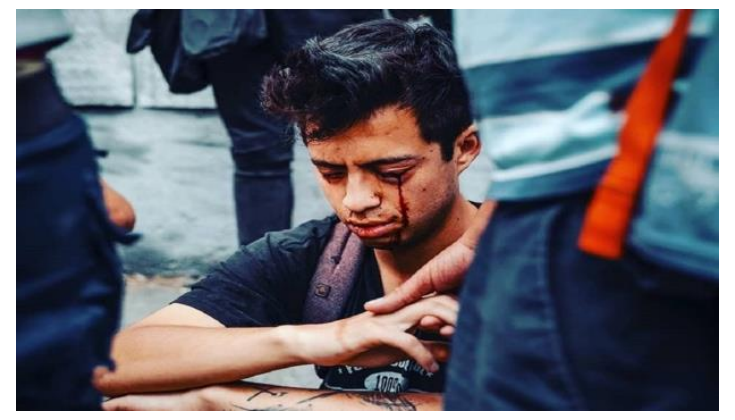

Figura 9. En Postales del estallido social chileno, 2020. 


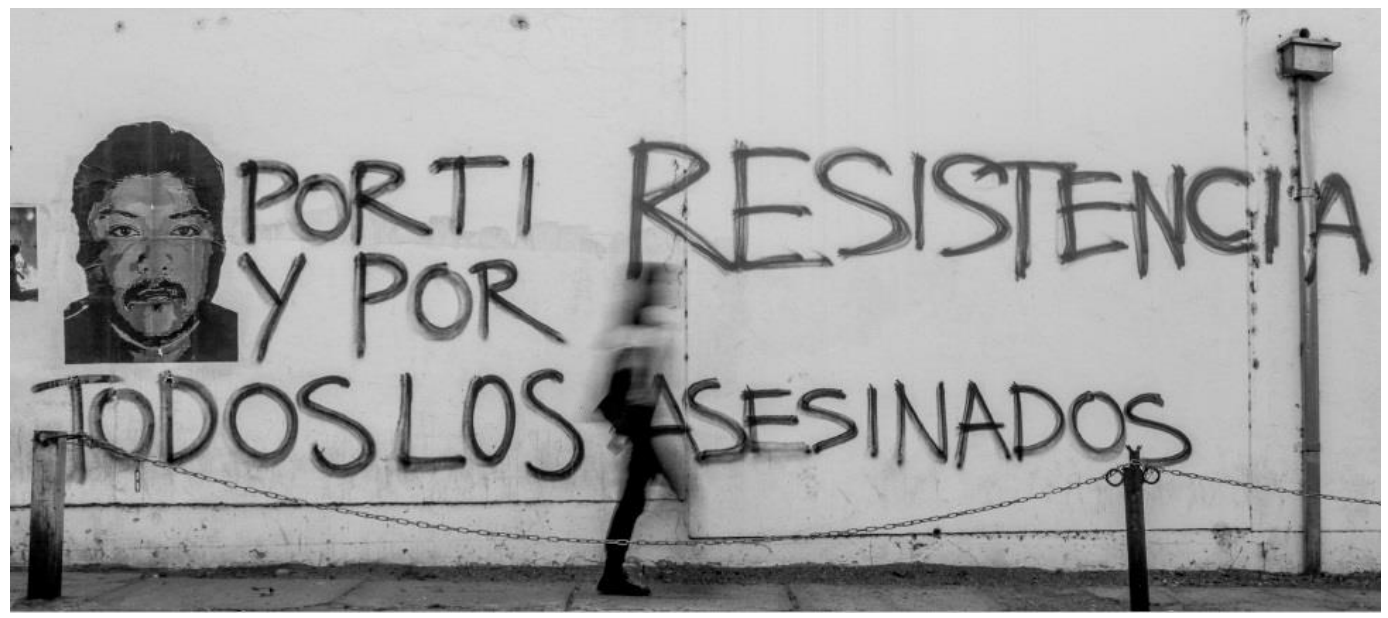

Figura 10. Echeverría et. al., 2019, p. 22.

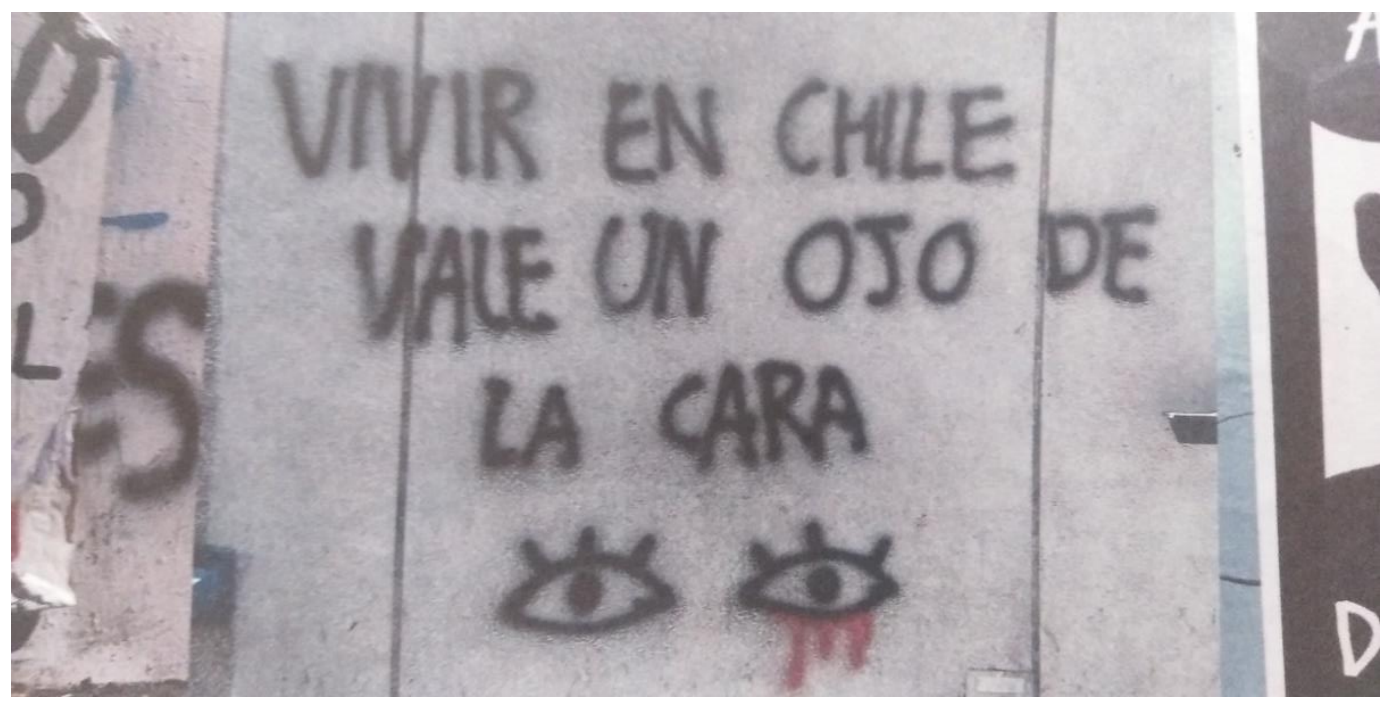

Dejando de lado las coincidencias entre el episodio descrito y los eventos ocurridos durante el estallido social (figura 10), queda de manifiesto el uso de la imagen fotográfica -anclada tanto de las pancartas como en redes sociales-como un medio de testimonio y denuncia de la violencia desatada por las fuerzas policiales. Y en este sentido, la fotografía como recurso, en ambos casos, comprende un combate a la indiferencia generada a partir de la publicidad y la imagen fugaz de los medios como la televisión, además de una forma de anteponerse ante el silencio de las autoridades y los medios oficiales ${ }^{8}$.

\footnotetext{
${ }^{8}$ No es menor, al respecto, que una de las bases retóricas de la narrativa de los hijos sea su fragmentariedad nuevamente asociada al 'corte' y la ruina- la cual "constituye igualmente un aporte a la reconstrucción de nuestra memoria elidida, ese ‘blanco agresivo' que Diamela Eltit describía a 30 años del Golpe” (Amaro, 2013, p. 112) y que fue base del silencio pactado por veintitrés años de gobiernos que asumieron las prácticas neoliberales. De este modo, se condice la confrontación contra el silencio de los padres y la confrontación que se evidencia, tanto en literatura como en las manifestaciones sociales, contra el silencio pactado de la historia y el Estado.
} 


\section{Joaquín Vargas}

Al mismo tiempo, el texto de Chilean Electric supone, como he mencionado, una resignificación del espacio por cuanto toma la fotografía, también, para la visibilización de los espacios que han sido 'oscurecidos' en la articulación de nuestra identidad. De este modo, hay una denuncia no sólo a partir de la violencia en dictadura, sino también de la violencia que significa la relegación o marginación de los cuerpos que incomodan -como los peruanos que pueblan la Plaza de Armas- y que, en este caso, son revelados mediante la escritura, lo que explicaría el sentido del mantra "Iluminar con la letra la temible oscuridad" que aparece en la novela: iluminar, dar a conocer por medio de la letra -la fotografía como testimonio- aquellas zonas del espacio -la ciudad y la memoria - que han sido oscurecidas y olvidadas.

Se evidencia, de este modo, el carácter performativo de la imagen que, dentro de la movilización social, no sólo toma un claro sentido de denuncia, sino también el ya mencionado sentido de resignificación y refundación de la identidad nacional a partir del reconocimiento de las minorías marginadas. En este contexto, es imprescindible hablar de la participación que tanto la lucha feminista como el movimiento LGBTIQ+ ha tenido durante los meses del estallido, por cuanto el espacio público de la ciudad carece de monumentalizaciones para los grupos minoritarios, como afirma Roberto Fernández Droguett. La intervención, que alcanzó niveles internacionales, del Colectivo LASTESIS con "Un violador en tu camino" (figura 11) es determinante en este sentido pues, al igual que las novelas de la memoria, otorgan voz a quienes han sido silenciados por años -en este caso, las mujeres que han sido víctimas de la violencia patriarcal.

Figura 11. En Postales del estallido social chileno, 2020.



Sin embargo, me interesa destacar aquí la influencia que tuvo la figura de Pedro Lemebel, por ejemplo, dentro de las movilizaciones de octubre de 2019, como se observa en la figura 12. Si lo pensamos dentro de la lógica de las contranarrativas urbanas, antes mencionadas, Márquez y Rozas establecen que hay un acto de refundación de la Universidad de Chile en el momento en que Pedro Lemebel y Francisco Casas realizan su performance, entrando desnudos sobre una yegua blanca a la casa de estudios. Al respecto, Márquez y Rozas afirman que hay una refundación 


\section{Joaquín Vargas}

simbólica del espacio desde la trasgresión del cuerpo homosexual, largamente silenciado y ocultado (2019, p. 55). El mismo episodio, y con el mismo tinte de renovación, es atendido por Juan Pablo Sutherland en Papelucho gay en dictadura (2019), cuando describe un sueño que comparte con Rodrigo Lira: "Hay un aire de fin de mundo, una yegua, una sacerdotisa, dos tipos en pelotas y apocalipsis en el viento de la tarde. Rodrigo Lira dice que son bellos maricas al ocaso. Callado los pierdo de vista en los jardines del Pedagógico" (2019, p. 104).

Figura 12. Rescatado de la cuenta de Instagram @ noesoriano.

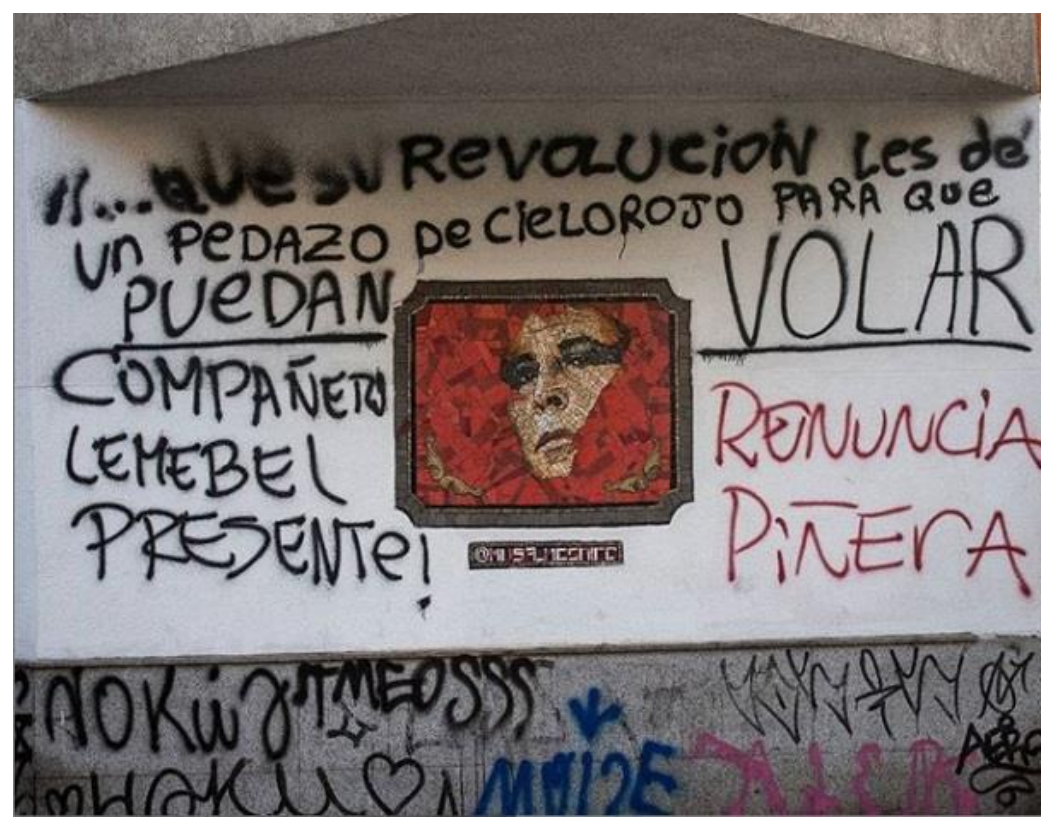

Figura 13. En Postales del estallido social chileno, 2020.

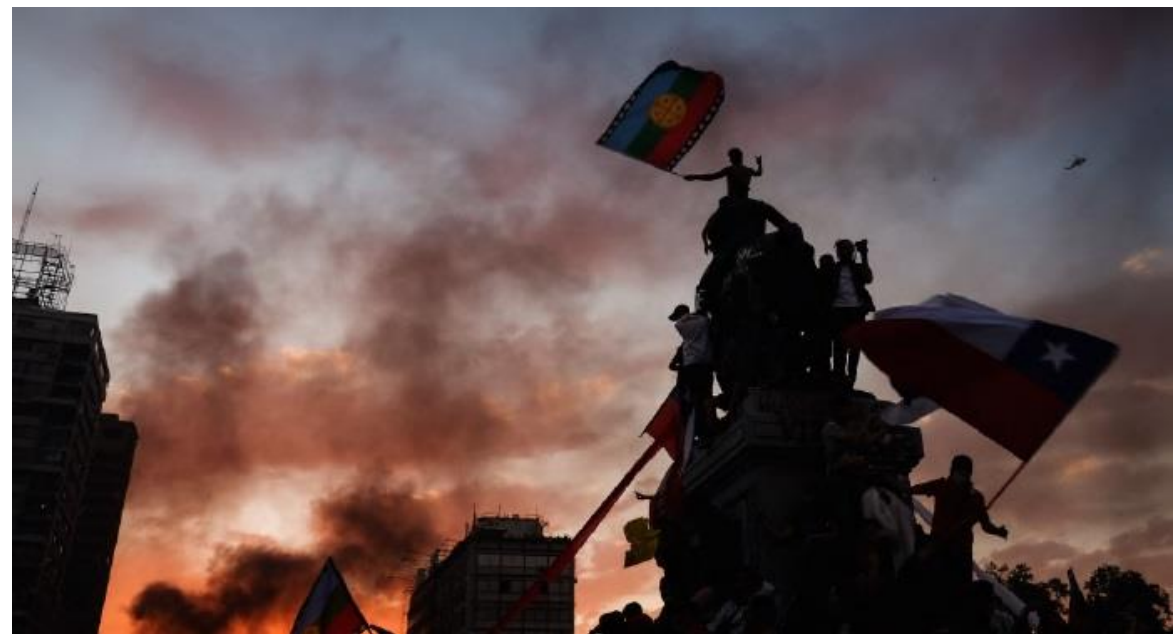


Literatura y memoria visual: cruces estético-performativos entre las narrativas de la memoria y el Estallido Social de octubre 2019

\section{Joaquín Vargas}

El carácter performativo de lo queer presente en la narrativa de Juan Pablo Sutherland contempla una forma de crear un nuevo marco referencial de la identidad, que ya no se sujeta a la convencionalidad de la heteronorma (Salomón, 2013). Del mismo modo, la acción de las Yeguas del Apocalipsis, descrita en el sueño del narrador de Papelucho gay en dictadura, implican una subversión de los signos por cuanto ironizan la figura del conquistador viril a caballo -en este caso, Pedro de Valdivia- con una referencia estética a Lady Godiva (Richard, 2018). Y de mismo modo, ocurre la ocupación del monumento al general Baquedano: su figura, también a caballo según la iconografía de las Yeguas del Apocalipsis, es subvertido como soporte de denuncia y visibilización de la diferencia, adquiriendo ese "aire de fin de mundo" que ha sido el más recordado emblema de las movilizaciones sociales de octubre de 2019, según atestigua la figura 13.

En suma, tanto las contranarrativas como la performatividad queer implican una resignificación, una subversión o trasgresión de los signos hegemónicos de nuestra identidad, y es ésta trasgresión la que vemos operar en la movilización social: subversión de los signos, subversión de los patrimonios y articulación de un nuevo marco referencial para nuestra identidad.

\section{Conclusión}

Frente al monumento y el diseño urbano que se impone como una narrativa hegemónica de nuestra identidad, que nos ordena socialmente en función de ese discurso homogeneizador que identifica Harvey (1990), las contranarrativas urbanas vienen a tensionar el habitar cotidiano y pasivo del ser en la ciudad. A partir del rayado, la intervención, la ruinación y la performance, las contranarrativas abren la discusión dentro de la llamada ciudad letrada que establece a la urbe, en su infraestructura y su distribución, como un discurso. Dicha discusión abre, a su vez, un proceso de resignificación del espacio, una codificación que hemos relacionado aquí con las articulaciones narrativas de la literatura chilena reciente, en función de una denuncia que trae a colación la problemática de la memoria en un contexto de blanqueamiento de la historia y el olvido. Resignificación que Lefebvre entiende como la articulación de contraespacios.

Lo que me ha interesado demostrar en este sentido es, finalmente, que en las contranarrativas que toman lugar durante las manifestaciones sociales que se gestan en octubre de 2019 -aunque, bien es sabido, existen desde hace mucho antes- podemos identificar relaciones de similitud y diálogo con la estética narrativa de la literatura reciente. Las nociones de la ruina, por un lado, y el uso performativo de la fotografía como medio de representación, han sido usados en la narrativa como una forma de anteponerse al lenguaje del mercado que instala como eje cultural las llamadas políticas del olvido. Del mismo modo, el escombro y el rayado rompen con el orden y silenciamiento de años de abuso y violencia estatal, llevando al plano del diseño urbano el descontento de las masas.

Podemos ver, entonces, que el estallido social de octubre de 2019 compone una estética visual en que destacan las contranarrativas urbanas como una forma de anteponerse, denunciar y enfrentarse a los discursos hegemónicos de nuestra identidad y nuestra historia. Dichas contranarrativas implican una resignificación del espacio urbano, de la misma manera que en la literatura se resignifica mediante la creación de espacios representacionales o contraespacios, en términos de Lefebvre. En ambos casos, se contempla una textualidad que pretende resaltar las experiencias ocultas y silenciadas de nuestro entorno, al punto que podemos afirmar que las contranarrativas de la ciudad no son sino las narrativas de nuestra memoria. 
Literatura y memoria visual: cruces estético-performativos entre las narrativas de la memoria y el Estallido Social de octubre 2019

\section{Joaquín Vargas}

\section{Referencias}

Alvarado, M. (1994). Paratexto. Buenos Aires: UBA.

Amaro, L. (2013). Formas de salir de casa, o cómo escapar del Ogro: relatos de filiación en la literatura chilena reciente. Literatura y Lingüística (29), 109-129. http://dx.doi.org/10.4067/S0716-58112014000100007

Anabalon, N. (2016). Escribir después del desastre: recuerdo y testimonio en Estrellas Muertas de Álvaro Bisama. Revista Catedral Tomada vol. 4 (6), 91-103.

Bajtín, M. (2011). Las fronteras del discurso. Borovsky, Luisa (trad). Buenos Aires: Las Cuarenta.

Barthes, R. (1989) La cámara lúcida: notas sobre la fotografía. Sala-Sanahuja, J. (trad.). Buenos Aires: Ed. Paidós, 2017.

Bisama, A. (2014). Taxidermia. Santiago: Alquimia Editores.

Bongers, W. (2018). Memoria, medios audiovisuales y literatura expandida en la narrativa chilena reciente (Baradit, Fernández, Zambra). Revista de Humanidades (37), 103-130.

Celedón, M. (2012). La Filial. Santiago de Chile: Alquimia Editores.

Cisternas, C. (2010). Introducción. Imagen de la ciudad en la literatura hispanoamericana y chilena contemporánea. Santiago: Editorial Universitaria.

Didi-Huberman, G. (2004). Imágenes pese a todo: Memoria visual del Holocausto. Barcelona: Ediciones Paidós Ibérica.

Echeverría, L., Rebolledo, J. y Tótoro, D. (2019). Hasta que valga la pena vivir. La revolución de octubre de 2019 en los muros de Santiago. Santiago: Ceibo Editores.

Fernández, N. (2012). Fuenzalida. Santiago de Chile: Ed. Random House Mondadori. (2015) Chilean Electric. Santiago: Alquimia Editores.

Fernández Droguett, R. (2019). Marchas y conmemoraciones. Santiago y el centro histórico. En F. Márquez (Ed.) Patrimonio: Contranarrativas urbanas (pp. 115-130). Santiago de Chile: Ediciones Universidad Alberto Hurtado.

Franz, C. (2001). La muralla enterrada. Santiago: Editorial Planeta.

Harvey, D. (1990). La condición de la posmodernidad: Investigación sobre los orígenes del cambio cultural. Eguía, M. (trad.). Buenos Aires: Amorrortu Editores, 1998.

Jeftanovic, A. (2007). Mapocho de Nona Fernández: La ciudad entre la colonización y la globalización. Chasqui: Revista de literatura latinoamericana (36), 73-84.

Kropotkin, P. (2014). La moral anarquista. Santiago de Chile: Ediciones Espartaco.

Locane, J. (2013). Ciudad y literatura. Apuntes para un modelo de abordaje de las ciudades textuales fundado en la teoría de Henri Lefebvre. Estudios de Teoría Literaria, 2 (4), 111124.

Márquez, F. y Rozas, V. (2019). Las heridas de la memoria. Palacio de la Moneda. En F. Márquez, (ed.) Patrimonio: Contranarrativas urbanas (pp. 37-52). Santiago de Chile: Ediciones Universidad Alberto Hurtado.

(2019). Ocupación y reclamo. Universidad de Chile. En F. Márquez, (Ed.) Patrimonio: Contranarrativas urbanas (pp. 53-74). Santiago de Chile: Ediciones Universidad Alberto Hurtado.

Márquez, F. (2020) Por una antropología de los escombros. El estallido social en Plaza Dignidad, Santiago de Chile. Revista 180, 45, 1-13.

http://dx.doi.org/1032995/rev180.Num-45.(2020)art-717

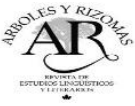


Literatura y memoria visual: cruces estético-performativos entre las narrativas de la memoria y el Estallido Social de octubre 2019

Joaquín Vargas

Mitchell, W.J.T. (2009). Teoría de la Imagen. España, Madrid: Akal.

Rama, A. (1998). La ciudad letrada. Montevideo: Arca.

Reyes Gil, S. (2020) Corte y conceptualismo en La Filial (2013) de Matías Celedón. Revista Letral (24), 139-158.

Richard, N. (2000). Imagen-recuerdo y borraduras. En N. Richard (Ed.) Políticas y estéticas de la memoria (pp. 165-172). Santiago de Chile: Editorial Cuarto Propio. (2001). Residuos y Metáforas (Ensayos de crítica cultural sobre el Chile de la Transición). Santiago de Chile: Editorial Cuarto Propio.

(2018). La contorsión-subversión travesti. Abismos temporales. Feminismo, estéticas travestis y teoría queer (pp. 41-55). Santiago de Chile: Ed. Metales Pesados.

Salomón, J. (2013). Identidad queer en la obra de Juan Pablo Sutherland. Revista Nomadías, (18), 67-84.

Segato, R. (2013). La escritura en el cuerpo de las mujeres asesinadas en Ciudad Juárez. Territorio, soberanía y crímenes de segundo estado. Buenos Aires: Tinta Limón Ediciones.

Sutherland, J. P. (2019). Papelucho gay en dictadura. Santiago de Chile: Alquimia Editores.

Todorov, T. (2008). Los abusos de la memoria. España, Barcelona: Ed. Paidós.

Trabuco Zerán, A. (2015). La Resta. Santiago de Chile: Tajamar Editores.

Vargas, J. (2019). Iluminar con la letra la temible oscuridad: Espacio y visualidad en la narrativa de Nona Fernández. Tesis para optar al grado de Magíster en Literatura Latinoamericana y Chilena, USACH.

Williams, R. (2000). Marxismo y Literatura. Barcelona: Ediciones Península. 